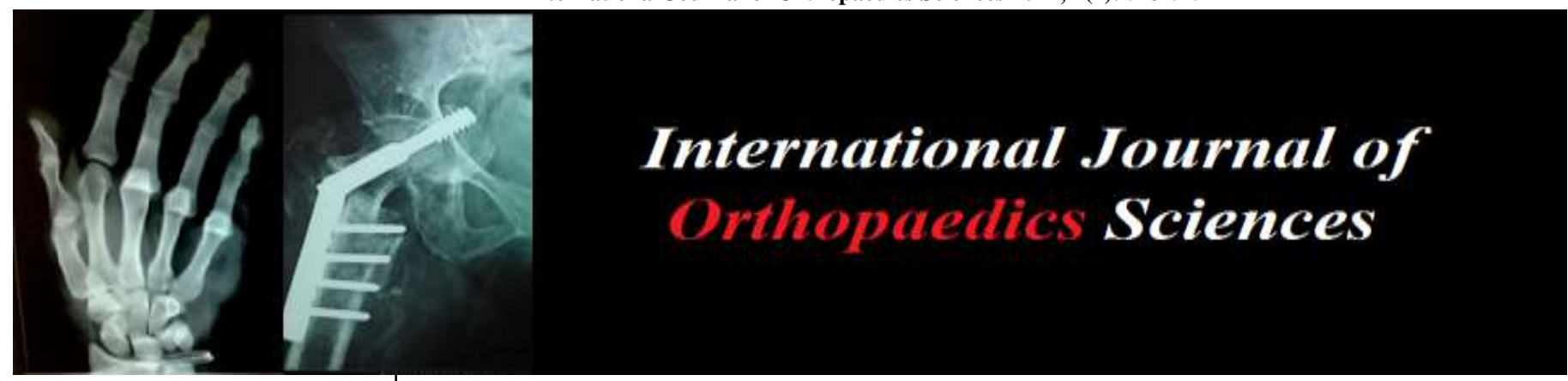

E-ISSN: 2395-1958

P-ISSN: 2706-6630

IJOS 2021; 7(2): 523-529

(C) 2021 IJOS

www.orthopaper.com

Received: 16-02-2021

Accepted: 23-03-2021

Nirav R Gupta

M.S. Orthopedics, Bonded

Assistant Professor, Lokmanya

Tilak Municipal Medical College

and General Hospital, Sion,

Mumbai, Maharashtra, India

Arvind B Goregaonkar

Professor and Head of

Department, Lokmanya Tilak

Municipal Medical College and

General Hospital, Sion, Mumbai,

Maharashtra, India

Akshay Nayak

M.S. Orthopedics, Bonded

Assistant Professor, Lokmanya

Tilak Municipal Medical College

and General Hospital, Sion,

Mumbai, Maharashtra, India

Shreenidhi Kulkarni

M.S. Orthopedics, Bonded

Assistant Professor, Lokmanya

Tilak Municipal Medical College and General Hospital, Sion,

Mumbai, Maharashtra, India

Vishal Raina

M.S. Orthopedics, Bonded

Assistant Professor, Lokmanya

Tilak Municipal Medical College and General Hospital, Sion,

Mumbai, Maharashtra, India

Corresponding Author:

Nirav R Gupta

M.S. Orthopedics, Bonded

Assistant Professor, Lokmanya

Tilak Municipal Medical College

and General Hospital, Sion,

Mumbai, Maharashtra, India

\section{Study of treatment modalities and short term clinicoradiological outcome of osteoporotic vertebral fractures in adults}

\author{
Nirav R Gupta, Arvind B Goregaonkar, Akshay Nayak, Shreenidhi \\ Kulkarni and Vishal Raina
}

DOI: https://doi.org/10.22271/ortho.2021.v7.i2g.2673

\section{Abstract}

Background: Vertebral compression fracture is the most common problem in old age causing incapacitating pain which produces significant morbidity, disability and mortality. On a global basis, Indians have the highest prevalence of osteopenia ${ }^{[1]}$. Compared to Western population, fractures related to osteoporosis in the Indians occur a decade earlier in age. On average 45 Lakh Indian females above $60 \mathrm{yrs}$ of age have a fractured spine compared to osteoporotic hip fractures every year which is 2.5 lakhs [2].

Materials and Methods: Single centre prospective study was conducted in tertiary care centre in Maharashtra during the period of February 2019 to January 2021. Minimum period of follow up was 1 year. VAS Score, ODI Score were used to calculate the functional outcome.

Results: The VAS Score in conservatively treated reduced from a mean of 8.2 preoperatively to 5.2 at 12 months. In surgically treated patients, the VAS Score reduced from a mean of 8 preoperatively to 2.4 at 12 months after balloon kyphoplasty/vertebroplasty whereas in posterior instrumented cases it reduced from a mean of 8.8 preoperatively to 2.5 at 12 months. Similarly ODI Score in conservatively treated patients reduced from a mean of 71.3 preoperatively to 47.1 at 12 months. In surgically treated patients the ODI Score reduced from a mean of 72.5 preoperatively to 26.1 at 12 months after balloon kyphoplasty/Vertebroplasty whereas in posterior instrumented cases the ODI Score reduced from a mean of 73.6 preoperatively to 27.1 at 12 months

Conclusion: From this study we conclude that all the three methods of management of osteoporotic vertebral fractures are significantly effective but proper patient selection and timely intervention is of utmost importance of optimal outcome.

Keywords: Osteoporotic vertebral fractures, vertebroplasty, balloon kyphoplasty, posterior instrumentation

\section{Introduction}

Vertebral compression fractures are the most common osteoporotic fractures, one vertebral compression fractures occurring every 45 seconds. 30-50\% of all the females develop vertebral compression fractures during their lifetime ${ }^{[3]}$. At age of 75 years $25 \%$ of females have atleast single vertebral compression fracture on an average which increases to $50 \%$ at the age of 80 years.

After one vertebral compression fracture there is 4 times increased risk of 2 nd vertebral compression fracture, after second fracture risk increases 12 times of further vertebral compression fractures. It has been estimated that annual cost -25 Billion Euros / year are being spent in the management of vertebral fractures ${ }^{[4]}$. The conventional treatment of these fractures includes analgesics, bed rest, life style modifications, bracing and supplementary osteoporotic interventions.

Approximately $33 \%$ of the patients do not respond to conventional pain medication and conservative treatment. This leads to reduced inactivity and mobility which in turn leads to further bone loss and other problems like atelectasis, pneumonias, deep vein thrombosis, pulmonary embolism and so on ${ }^{[5]}$. In senior citizens, these morbidities cause loss of independence and reduced daily activities leading to social isolation and depression ${ }^{[6]}$. 
The fractured osteoporotic vertebrae may also progress to collapse and may lead to progressive burst fractures leading to kyphosis with variable degrees of cord compressions and further complications. So the need to stabilize the fractures besides the medical treatment and braces is mandatory. Vertebroplasty a type of vertebral augmentation techniques is one of the important recent advances minimally invasive approaches in wedge compression fractures which offer symptomatic immediate long lasting pain relief significantly [7]

\section{Aims and Objectives}

To study the various available treatment options for osteoporotic vertebral fractures

To compare the functional and radiological outcome of osteoporotic vertebral fractures treated by various modalities.

\section{Materials and methods}

Single centre prospective study was conducted in tertiary care centre in Maharashtra during the period of February 2019 to January 2021. 30 Indian patients of both sex more than $50 \mathrm{yrs}$ of age with vertebral fractures were included with DEXA scan proven osteoporosis. Minimum period of follow up was 1 year. Patients with metastatic/neoplastic pathological fracture and presence of spinal tuberculosis or infective pathology were excluded. VAS Score, ODI Score were used to calculate the functional outcome.

\section{Methodology}

All patients from OPD or Ward fulfilling the inclusion criteria were included in the study after taking their consent and their baseline details were collected which includes their demographics, calcium profile, radiographs, DEXA Scans, CT scans and MRI of spine, neurological examination, pain scores. Patients were divided in three groups

Group A included patients with fresh, stable vertebral fractures, without neurodeficit, without major disability with respect to pain and these were treated by conservative management.

Group B included patients with severe back pain, failed conservative treatment, pseudoathrosis on radiographs, without bony retropulsion or cord compression and were treated with balloon kyphoplasty or vertebroplasty.

Group $\mathrm{C}$ included patients with bony retropulsion with neurological compromise, spinal instability with or without severe disability, multilevel fracture and these patients required instrumentation with pedicular screws and rods with or without interbody fusion.

Medical treatment of osteoporosis was done in all cases with calcium and Vit D3 supplements, bisphosphonates and PTH as required, bracing wherever necessary, followed by physical rehabilitation.

Surgery were done as per standard protocols through posterior approach by senior consultants. Balloon kyphoplasty or Vertebroplasty was performed through Transpedicular approach.

These patients were followed up at 1 month, 3 month, 6 month and 1 year.

Follow up included assessment of radiological investigations (XRAY, CT scan and MRI), blood investigation, neurological examination and functional scores (VAS and ODI score).

\section{Results}

Descriptive statistics such as mean and standard deviation (SD) for continuous variables, frequencies and percentages were calculated for categorical Variables. Association between Variables was analyzed by using Chi-Square test for categorical Variables. Comparison of Mean of Quantitative Variables were analyzed using Repeated measure ANOVA (Analysis of Variance). Bar charts and Pie charts were used for visual representation of the analyzed data. Level of significance was set at 0.05 .

The minimum age was 55yrs and maximum age was $72 \mathrm{yrs}$. Mean age was 64 years. All females in this study were postmenopausal $(100 \%)$. Of the 30 patients included 20 patients were female and 10 male.

There were various levels of fractures noted in the study, dorsolumbar spine being the most commonly affectedwith the most common being L1 fractures, in 8 of the patients(26.7\%) and the second most common being D12 fracture, 7 patients $(23.3 \%)$. The most common mode of injury was slip and fall.

Table 1: Comparison of Denis Classification between Management Group ( $\mathrm{N}=30$ )

\begin{tabular}{|c|c|c|c|c|}
\hline \multirow[b]{2}{*}{ Denis Classification } & \multicolumn{3}{|c|}{ Management Group } & \multirow[b]{2}{*}{ Total } \\
\hline & $\begin{array}{c}\text { Group A }(\mathrm{n}=10) \\
\text { n }(\%)\end{array}$ & $\begin{array}{c}\text { Group B }(n=10) \\
\text { n }(\%)\end{array}$ & $\begin{array}{c}\text { Group C }(n=10) \\
n(\%)\end{array}$ & \\
\hline A & $1(10.0)$ & $1(10.0)$ & $1(10.0)$ & $3(10.0)$ \\
\hline $\mathrm{B}$ & $8(80.0)$ & $3(30.0)$ & $1(10.0)$ & $12(40.0)$ \\
\hline $\mathrm{C}$ & $1(10.0)$ & $2(20.0)$ & & $3(10.0)$ \\
\hline $\mathrm{D}$ & & $4(40.0)$ & $8(80.0)$ & $12(40.0)$ \\
\hline
\end{tabular}

Table 2 - The mean kyphotic angle in group A preoperatively was $11.2 \pm 2.53$ which on follow-up up to 3 months remained constant. At 6 months there was slight increase in the mean kyphotic angle, being $11.6 \pm 2.27$ but at the end of 12 months it became $12.2 \pm 2.74$.

In group B preoperative mean kyphotic angle was $11.4 \pm 2.31$ which in immediate postoperative period was reduced to $5.6 \pm$ 0.69 and remained the same for up to 3 months, at 6 months there was an increase in the mean kyphotic angle to $7.3 \pm$ 2.21 and it remained the same till the end of the study.

$P$ value was $<0.001$ suggesting a significant change.

In group $\mathrm{C}$ the mean kyphotic angle preoperatively was 13.2 \pm 2.53 which in immediate postoperative period was reduced to $7.00 \pm 1.05$ which remained constant and did not change significantly till the end of 12 months $(7.2 \pm 1.05)$.

$P$ value was $<0.001$ suggesting a significant change. 
Table 2: Comparison of Kyphotic Angle between Management Group (N=30)

\begin{tabular}{|c|c|c|c|c|c|}
\hline \multirow[b]{2}{*}{ Kyphotic Angle } & \multicolumn{3}{|c|}{ Management Group } & \multirow[b]{2}{*}{ Total } & \multirow[b]{2}{*}{ P Value } \\
\hline & $\begin{array}{l}\text { Group A }(\mathbf{n}=10) \\
\text { Mean }(\text { SD) }\end{array}$ & $\begin{array}{l}\text { Group B (n=10) } \\
\text { Mean (SD) }\end{array}$ & $\begin{array}{c}\text { Group C }(n=10) \\
\text { Mean (SD) }\end{array}$ & & \\
\hline Pre-op & $11.20(2.53)$ & $11.40(2.31)$ & $13.20(2.53)$ & $11.93(2.54)$ & 0.155 \\
\hline Post-op & & $5.6090 .69)$ & $7.00(1.05)$ & $6.30(1.12)$ & $0.003^{*}$ \\
\hline At 1 month & $11.20(2.53)$ & $5.60(0.69)$ & $7.00(1.05)$ & $7.93(2.88)$ & $<0.001^{*}$ \\
\hline At 3 months & $11.20(2.34)$ & $5.80(1.03)$ & $7.00(1.05)$ & $8.00(2.81)$ & $<0.001^{*}$ \\
\hline At 6 months & $11.60(2.27)$ & $7.30(2.21)$ & $7.00(1.05)$ & $8.63(2.83)$ & $<0.001 *$ \\
\hline At 12 months & $12.20(2.74)$ & $7.30(2.21)$ & $7.20(1.05)$ & $8.90(3.13)$ & $<0.001 *$ \\
\hline
\end{tabular}

Table 3- The mean anterior vertebral height in group A pretreatment was $25.1 \pm 4.79(\mathrm{~mm})$ which on follow-up up to 3 months became $25.6 \pm 2.27$ but at the end of 12 months it reduced to $24.7+2.35$.

In group $\mathrm{B}$ preoperative mean anterior vertebral height was $26.3+1.63$ which in immediate postoperative period was increased to $27.6 \pm 1.71$ and remained the same till the end of the study, at 12 month being $27.1 \pm 1.91$. P value was $<0.001$ suggesting a significant change.

In group $\mathrm{C}$ the mean anterior vertebral height preoperatively was $26.1 \pm 0.87$ which in immediate postoperative period was increased to a mean of $29.1+0.87$ which remained constant and did not change significantly till the end of 12 months. $P$ value was $<0.001$ suggesting a significant change

Table 3: Comparison of Anterior Vertebral Height between Management Group (N=30)

\begin{tabular}{|c|c|c|c|c|c|}
\hline \multirow{2}{*}{ Anterior Vertebral Height } & \multicolumn{3}{|c|}{ Management Group } & \multirow{2}{*}{ P Value } \\
\cline { 2 - 5 } & $\begin{array}{c}\text { Group A (n=10) } \\
\text { Mean (SD) }\end{array}$ & $\begin{array}{c}\text { Group B (n=10) } \\
\text { Mean (SD) }\end{array}$ & $\begin{array}{c}\text { Group C (n=10) } \\
\text { Mean (SD) }\end{array}$ & Total & (SD) \\
\hline Pre-op & $25.10(4.79)$ & $26.30(1.63)$ & $26.10(0.87)$ & $25.83(2.91)$ & 0.631 \\
\hline Post-op & & $27.60(1.71)$ & $29.10(0.87)$ & $28.35(1.53)$ & $0.024^{*}$ \\
\hline At 1 month & $26.1091 .96)$ & $27.60(1.71)$ & $29.10(0.87)$ & $27.60(1.97)$ & $0.001^{*}$ \\
\hline At 3 months & $25.60(2.27)$ & $27.40(1.77)$ & $29.10(0.87)$ & $27.37(2.22)$ & $0.001^{*}$ \\
\hline At 6 months & $25.20(1.93)$ & $27.10(1.91)$ & $29.10(0.87)$ & $27.13(2.27)$ & $<0.001^{*}$ \\
\hline At 12 months & $24.70(2.35)$ & $27.10(1.91)$ & $29.10(0.87)$ & $26.97(2.53)$ & $<0.001^{*}$ \\
\hline \multicolumn{7}{|c|}{ ANOVA, P Value *Significant } & \\
\hline
\end{tabular}

Table 4- The VAS Score in group A reduced from a mean of $8.2 \pm 0.63$ preoperatively to $6.8 \pm 1.03$ at 1 month of treatment and to $5.2 \pm 0.63$ at 12 months.

In group B the VAS Score reduced from a mean of $8 \pm 0.66$ preoperatively to $4.5 \pm 0.85$ immediate postop and to $2.4 \pm$ 0.84 at 12 months.

Whereas in group $\mathrm{C}$ the VAS Score reduced from a mean of $8.8 \pm 0.82$ preoperatively to $5 \pm 0.47$ immediate postop and to
$2.5 \pm 0.52$ at 12 months

Preoperative VAS score versus VAS score at immediate, one month, three months, six months and 12 month postop in group $\mathrm{B}$ and group $\mathrm{C}$ showed that $\mathrm{p}$ value $<0.001$ in all postoperative period, so it was a significant.

Statistically, we noticed significant pain relief in immediate postoperative period which was maintained till the end of 12 months.

Table 4: Comparison of VAS Score between Management Group (N=30)

\begin{tabular}{|c|c|c|c|c|c|}
\hline \multirow[b]{2}{*}{ VAS Score } & \multicolumn{3}{|c|}{ Management Group } & \multirow[b]{2}{*}{ Total } & \multirow[b]{2}{*}{ P Value } \\
\hline & $\begin{array}{c}\text { Group A }(n=10) \\
\text { Mean }(\text { SD })\end{array}$ & $\begin{array}{c}\text { Group B }(\mathbf{n}=10) \\
\text { Mean }(\mathrm{SD})\end{array}$ & $\begin{array}{l}\text { Group C }(\mathbf{n}=10) \\
\text { Mean (SD) }\end{array}$ & & \\
\hline Pre-op & $8.20(0.63)$ & $8.00(0.66)$ & $8.30(0.82)$ & $8.17(0.69)$ & 0.636 \\
\hline Post-op & & $4.50(0.85)$ & $5.0090 .47)$ & $4.75(0.71)$ & 0.121 \\
\hline At 1 month & $6.80(1.03)$ & $2.60(1.17)$ & $2.60(0.51)$ & $4.00(2.21)$ & $<0.001 *$ \\
\hline At 3 months & $5.90(0.99)$ & $2.40(0.84)$ & $2.60(0.51)$ & $3.63(1.81)$ & $<0.001 *$ \\
\hline At 6 months & $5.40(0.84)$ & $2.40(0.84)$ & $2.60(0.51)$ & $3.47(1.57)$ & $<0.001 *$ \\
\hline At 12 months & $5.20(0.63)$ & $2.40(0.84)$ & $2.50(0.52)$ & $3.37(1.47)$ & $<0.001 *$ \\
\hline \multicolumn{6}{|c|}{ ANOVA, $\mathrm{P}$ Value $*$ Significant } \\
\hline
\end{tabular}

Table 5-The ODI Score in group A reduced from a mean of $71.3 \pm 6.6$ preoperatively to $54.4+6.29$ at 1 month of treatment and to $47.1 \pm 4.43$ at 12 months.

In group B the ODI Score reduced from a mean of $72.5 \pm 3.13$ preoperatively to $35.4 \pm 4.16$ immediate postop and to $26.1 \pm$ 2.76 at 12 months.

Whereas in group $\mathrm{C}$ the VAS Score reduced from a mean of
$73.6 \pm 6.05$ preoperatively to $39 \pm 3.05$ immediate postop and to $27.1 \pm 2.47$ at 12 months.

The results interpreted from this table showed that $\mathrm{p}$ value < 0.001 in all postoperative periods, so it was a statistically significant. It means that quality of life have been improved significantly in immediate postoperative period which was maintained at the end of 12 months also. 
Table 5: Comparison of ODI Score between Management Group (N=30)

\begin{tabular}{|c|c|c|c|c|c|}
\hline \multirow[b]{2}{*}{ ODI Score } & \multicolumn{3}{|c|}{ Management Group } & \multirow[b]{2}{*}{ Total } & \multirow[b]{2}{*}{ P Value } \\
\hline & $\begin{array}{c}\text { Group A }(n=10) \\
\text { Mean (SD) }\end{array}$ & $\begin{array}{c}\text { Group B }(\mathbf{n}=10) \\
\text { Mean (SD) }\end{array}$ & $\begin{array}{c}\text { Group C }(n=10) \\
\text { Mean (SD) }\end{array}$ & & \\
\hline Pre-op & $71.30(6.60)$ & $72.50(3.13)$ & $73.60(6.05)$ & $72.47(5.37)$ & 0.648 \\
\hline Post-op & & $35.40(4.16)$ & $39.00(3.05)$ & $39.41(8.17)$ & $<0.001 *$ \\
\hline At 1 month & $54.40(6.29)$ & $30.20(1.47)$ & $32.20(2.78)$ & $38.93(11.82)$ & $<0.001 *$ \\
\hline At 3 months & $48.90(5.70)$ & $26.10(2.76)$ & $27.10(2.47)$ & $34.03(11.35)$ & $<0.001 *$ \\
\hline At 6 months & $47.30(4.71)$ & $26.10(2.76)$ & $27.10(2.47)$ & $33.50(10.48)$ & $<0.001 *$ \\
\hline At 12 months & $47.10(4.43)$ & $26.10(2.76)$ & $27.10(2.47)$ & $33.43(10.35)$ & $<0.001 *$ \\
\hline
\end{tabular}

\section{Complications}

Only 1 patient from group B had intraoperative complication of cement leak. No other complications were noted in this study

\section{CASE}

66 year old female, k/c/o DM D11 osteoporotic vertebral fracture after slip and fall Fracture classification: AO- Grade A1, Denis- Grade B Neurological status - ASIA E

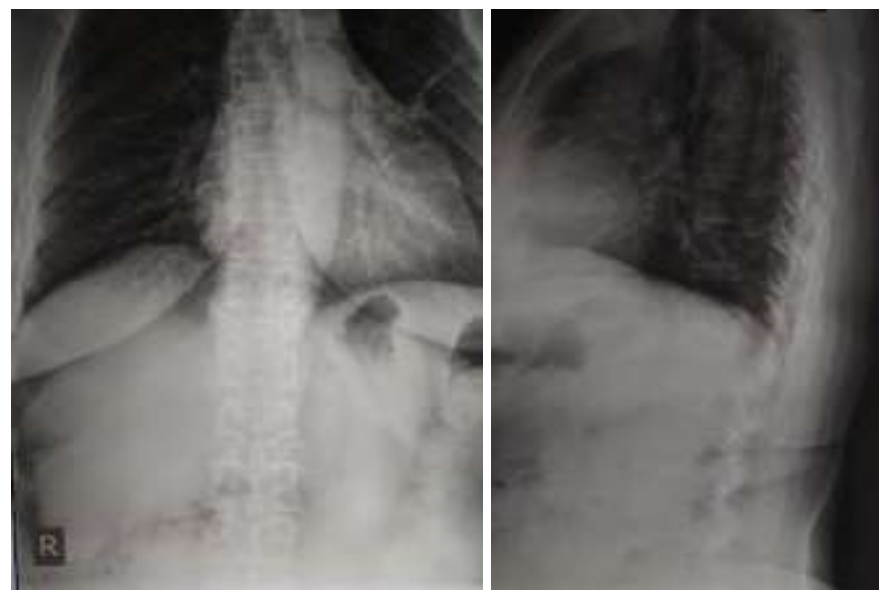

Fig 1: Preoperative X-rays
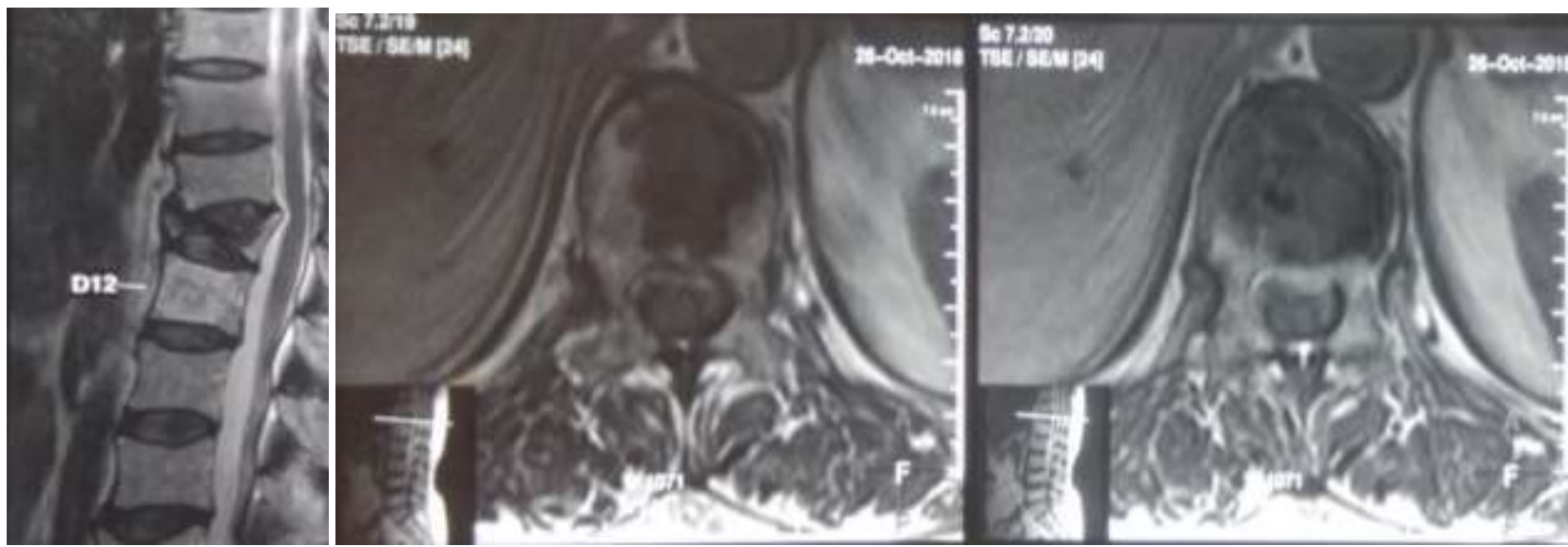

Fig 2: Preoperative MRI
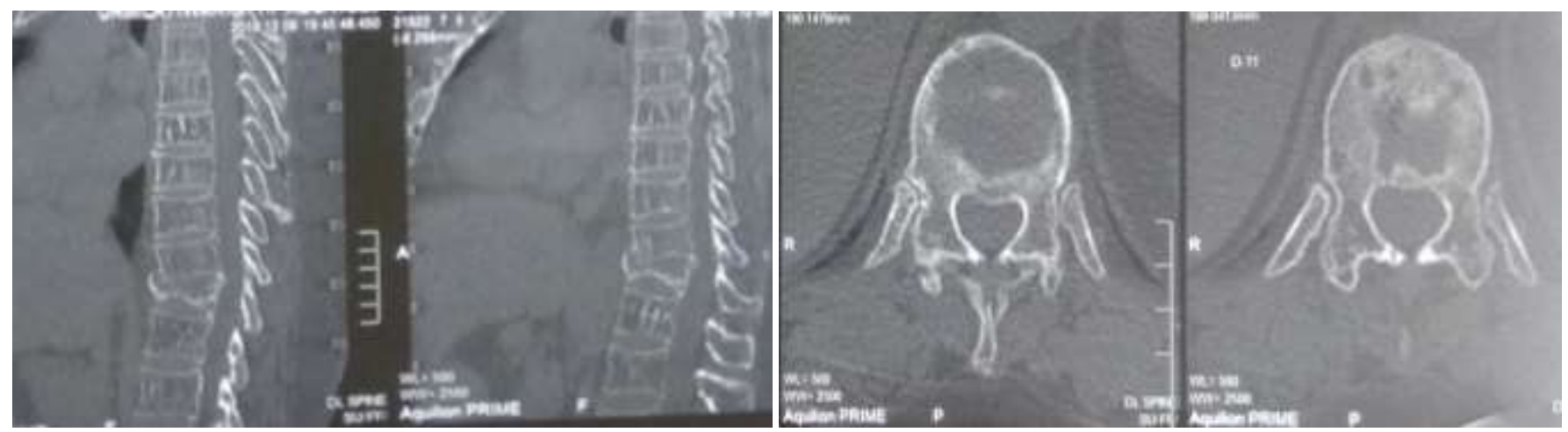

Fig 3: Preoperative CT Scan 


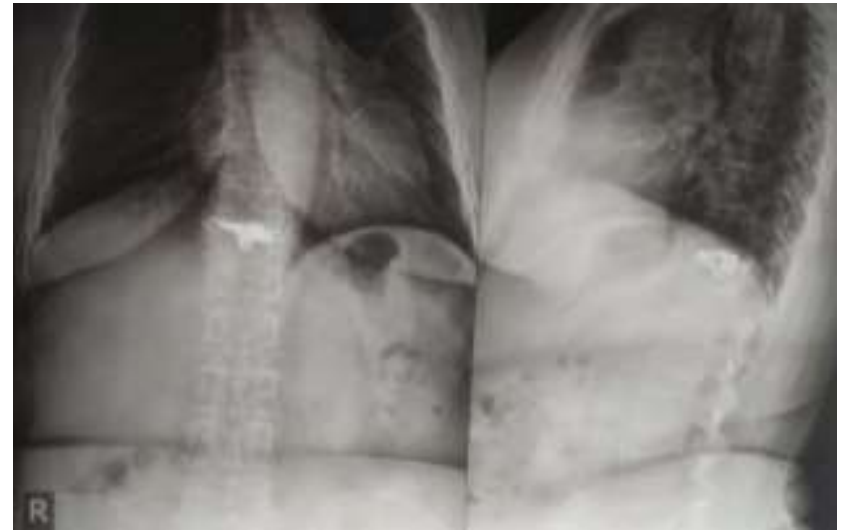

Fig 4: Immediate postoperative X-rays

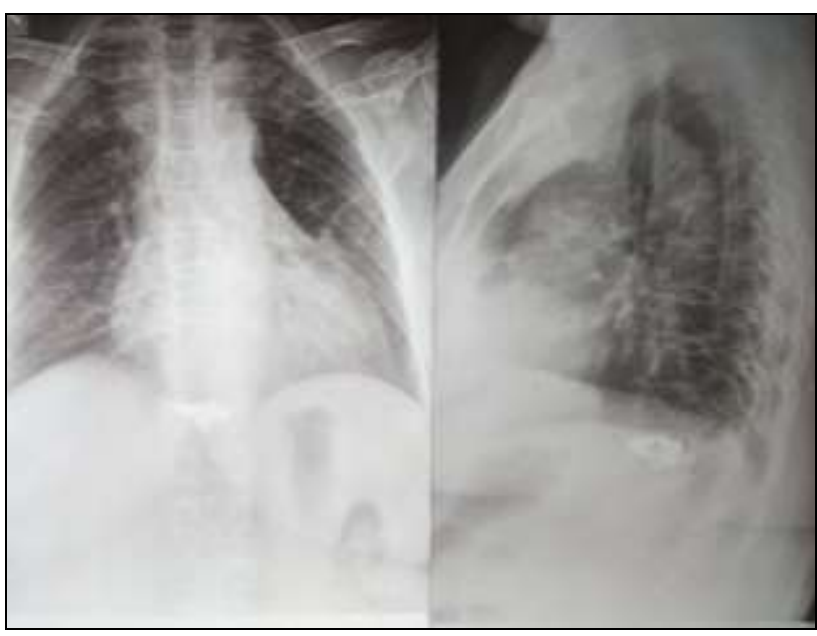

Fig 5: 1 year postoperative follow up x-ray

\section{Discussion}

Our study reports patient profile, treatment modalities and short-term functional outcome in the management of osteoporotic wedge compression fractures in patients with established osteoporosis confirmed by DEXA scan in urban population.

The study showed a predominantly female population, with the male: female ratio of 1:2. Although European Prospective Osteoporosis Study (EPOS) group had showed almost equal distribution amongst 3174 males and 3614 females, in a ratio of $1: 1.13^{[8]}$. All women were postmenopausal. Involutional bone loss starts between the ages of 35-40 yrs in both sexes, but there is an acceleration of bone loss in the decade after menopause in the female sex, referred to as type I osteoporosis. Within the first decade after menopause, bone loss affecting the lumbar spine nearly triples in women ${ }^{[9]}$. Pinheiro MM et al. also stated that menopause is the main factor associated with low trauma fracture ${ }^{[10]}$. Low calcium and vitamin $\mathrm{D}$ intake become additive insults in the microarchitectural deterioration ${ }^{[11]}$.

Back pain was the universal symptom seen in all patients, followed by deformity of the back. Francis RM et al. noted that only one third vertebral fractures come to medical attention where they typically present with acute back pain, but other presentations include deformity secondary to loss of height and increasing kyphosis ${ }^{[12]}$.

Lyritis et al. studied the natural history of osteoporotic vertebral fractures in 210 postmenopausal women and identified two groups ${ }^{[13]}$. In individuals with type I fractures, the osteoporotic vertebral fractures were radiographically evident and a single episode of pain was severe and acute, persisting for four to eight weeks. In type II fractures, the fracture was not clear radiographically, but a wedge deformity gradually developed over the next few months. The pain in type II fractures was less severe and of shorter duration than type I.

Neurological involvement as a direct consequence of the vertebral fracture was seen only in two patient. Spinal cord compression and myelopathy is not a common finding in vertebral osteoporotic fractures ${ }^{[14-15]}$, as there is no structural interruption of the posterior wall or middle column of the vertebral body. Although rare, some patients with osteoporotic vertebral compression fractures may present with neurological involvement ${ }^{[16]}$. Twenty to thirty percent vertebral compression fractures are multiple ${ }^{[17]}$. Isolated osteoporotic fractures above the level of T4 are uncommon and, even in patients with osteoporosis, should raise the suspicion of another underlying disease process ${ }^{[18]}$.

This study is significant because it used both radiological and clinical data to assess the efficacy of the various treatment option available with us. Conservative treatment is the traditional line of management of osteoporotic vertebral fractures. Short period of bed rest, analgesic medications, antiosteoporosis pharmacotherapy, bracing support for the fracture along with guided physical therapy and postural correction aid in lasting alleviation of the pain. According to Park YS et al., patients with established osteoporotic fractures should be confined to bed for two to three days, accompanied by the use of analgesics, hot packs, massage, and lumbar orthosis. Francis RM et al. stated that the management of patients with acute vertebral fractures should include measures to reduce pain, improve mobility, and treatment for osteoporosis. For the prevention and treatment of chronic pain, the back muscles should be strengthened with manual therapies and exercise intervention. Physical rehabilitation has a beneficial effect on bone metabolism, bone turnover, and bone mineral content. A number of systematic reviews and meta-analyses report the positive effects of exercise on bone mineral density, muscle strength, and quality of life, in men and women with osteoporosis or low BMD [19]. Spinal orthoses reduce pain by reducing mobility, decreasing postural flexion and providing axial support in patients with muscle fatigue and spasm.

Complications associated with conservative management should be borne in mind while instituting the treatment. Bed rest causes accelerated bone loss and loss of muscle strength [20]. Immobilization also leads to adverse effects on cardiac and pulmonary function in the geriatric population. Marshall $\mathrm{D}$ et al. advocated against the use of brace or corset as it immobilizes the spine, thereby aggravating bone loss and wasting of the surrounding muscles ${ }^{[21]}$.

In our study, with conservative treatment, there was a significant improvement in the VAS score for the back pain from 8.2 to 5.2 and a significant improvement in the ODI score from 71.3 to 47.1 at 12 months. Diamond HT et al. ${ }^{[22]}$, had noted $61 \%$ reduction in VAS pain scores at six weeks following initiation of conservative treatment and $71 \%$ reduction at six to 12 months. They also noted $31 \%$ improvement in physical functioning measured by Barthel index, at six weeks, which increased to $39 \%$ improvement at six to 12 months. The serum calcium, phosphorus, and vitamin D3 values showed improvement with conservative treatment, a direct result of the supplementation of calcium, vitamin D3, and bisphosphonates. Vitamin D plays a key role in calcium-phosphorus homeostasis. When vitamin D deficiency is not an issue, upto $30 \%$ to $40 \%$ of total dietary calcium is absorbed. Thus supplementation of calcium and 
vitamin D synergistically improve bone mineralization.

Vertebroplasty has gained popularity in the last 20 years due to its minimally invasive nature for the treatment of osteoporotic vertebral fractures and its efficacy in eliminating or substantially decreasing the pain experienced by this patient group. This type of vertebral augmentation procedure is accepted as a one of the most important and cost effective minimally-invasive treatment in these fracture management. In the last decade, a multiple studies have done and proven the reliability, efficacy, safety and cost-effectiveness of this treatment. In our study, we found a marked reduction in low back ache which is clinically as well as statistically significant in terms of reduced analgesic intake, and marked increase in quality of life. Our study has showed minimal cement extrusion rates when compared to other studies it was a much lesser asymptomatic cement extrusions ${ }^{[23]}$. There were no major complications in our study. No additional prophylactic vertebroplasty of adjacent and nonadjacent vertebral bodies was done as preventive measure of further future fractures. McGraw and colleagues studied results from 135 venographies in 96 vertebroplasties provided useful information for PMMA flow characteristics [24]. A metaanalysis also reported a success rate of $87 \%{ }^{[25]}$.

In this study there was a significant back pain reduction in immediate post operative period, maintained till the end of 12 month which was measured using VAS score and ODI score. The pain reduction is significant and it is relevant clinically. It also reveals the fact that the pain relief, reduced the need for analgesics, and increased the Quality of life after Vertebroplasty to a great extent.

Posterior instrumentation and transpedicular bone grafting are reported to give satisfactory results in terms of pain relief and correction of the kyphotic deformity. Screw pull-out is a significant concern in osteoporotic patients. Loss of mineral content, thinning of trabeculae as well as enlargement of Haversian and marrow spaces in osteoporosis reduces structural strength of cancellous bone ${ }^{[26]}$. We did not tap the cancellous matrix so that it could be compressed during screw insertion having a better purchase. Halvorson et al. ${ }^{[27]}$ and Benzel demonstrated that tapping decreased pullout resistance in osteoporotic bone. We avoided excessive bending of the rod so as to create a splint for load sharing of the spine. We also avoided rods that were too straight, for fear that cantilever force could pull out the pedicle screws ${ }^{[28]}$.

We prefer posterior instrumentation to anterior instrumentation and believe that a long rod and short fusion construct (load-sharing principle) ${ }^{[29]}$ was strong enough to stabilize the osteoporotic fracture. Moon et al. ${ }^{[30]}$ compared the effectiveness of long segment and short segment fixation in thoracic and lumbar fractures and reported that long and short rod fusion was more effective than the short rod and fusion construct, although it leads to wider immobilization of normal segments.

In one patient with multiple level wedge compression fracture both with old and new was treated with posterior stabilization. In few other patient with $>50 \%$ compression, initially conservative management was done but patient has persistent pain so we did posterior stabilization by which later patient had relieved of pain. Transpedicular bone grafting was introduced by Daniaux ${ }^{[31]}$ in 1986 to achieve an interbody fusion. This method was also used by other authors to treat thoracolumbar fracture. In addition to posterior instrumentation, we adopted this method to re-establish the load-bearing-capable anterior column. Bone graft itself has the same Young's modulus rather than polymethylmetacrylate
(PMMA), thus the risk of fracture at the vertebrae above and below the pathological vertebra is reduced ${ }^{[32]}$. We prefer vertebroplasty or kyphoplasty in those whose general condition is frail or undernourished. This study examining Vertebroplasty/balloon kyphoplasty and posterior instrumentaion for osteoporotic compression fractures indicates that, overall the procedures reduce pain and improve function and quality of life as compared with conservative treatment.

\section{Conclusion}

Conservative management advocated as the primary means of treatment for osteoporotic fractures showed a decrease in VAS Score and ODI Score over the period of 12 months. The radiological parameters however did not show a significant change. Balloon kyphoplasty/Vertebroplasty and Posterior Instrumentation both as a treatment option for osteoporotic vertebral fracture are equally effective and showed a significant improvement in VAS and ODI Score in immediate postoperative period and remained same up to 12 months. There was restoration of anterior vertebral height and kyphotic angle to near normal values and it remained the same throughout the study period.

From this study we conclude that all the three methods of management of osteoporotic vertebral fractures are significantly effective but proper patient selection and timely intervention is of utmost importance of optimal outcome.

There is no Conflict of interest.

Limitation of the study The drawbacks of our study are a small sample size of patients, lack of a comparative control group and a short period of observational follow-up.

\section{References}

1. Meeta Singh, Navneet Magon, Tanvir Singh. Major and minor discordance in the diagnosis of postmenopausal osteoporosis among Indian women using hip and spine dual-energy X-ray absorptiometry. J Midlife Health. 2012;3(2):76-80.

2. John A Sunyecz. The use of calcium and vitamin D in the management of osteoporosis. Ther Clin Risk Manag. 2008;4(4):827-836.

3. Michael K Shindle, Lisa Shindle, Michael J Gardner, Joseph M Lane, Supportive. Care Aspects of Vertebroplasty and Kyphoplasty in Patients with Cancer. Supportive Cancer Therapy 2006;3(2):214-219.

4. Gemma Marcucci1 and Maria Luisa Brandi. Kyphoplasty and vertebroplasty in the management of osteoporosis with subsequent vertebral compression fractures Clin Cases Miner Bone Metab 2010; 7(1):51-60.

5. Daniela Alexandru, William SO. Evaluation and Management of Vertebral Compression Fractures.Perm J. 2012; 16(4):46-51.

6. Kimi et al. Kondo.Osteoporotic Vertebral Compression Fractures and Vertebral Augmentation.Semin Intervent Radiol. 2008; 25(4):413-424

7. Eckel TS, Olan W. Vertebroplasty and vertebral augmentation techniques. Tech Vasc Interv Radiol 2009; 12(1):44-50.

8. European Prospective Osteoporosis Study (EPOS) Group: Incidence of vertebral fracture in Europe: results from the European Prospective Osteoporosis Study (EPOS). J Bone Miner Res 2002; 17:716-724.

9. Warming L, Hassager C, Christiansen C. Changes in bone mineral density with age in men and women: a longitudinal study. Osteoporos Int. 2002; 13:105-112. 
10. Pinheiro MM, Reis Neto ET, Machado FS et al.: Risk factors for osteoporotic fractures and low bone density in pre and postmenopausal women. Rev Saúde Pública 2010; 44:479-485.

11. Nevitt MC, Cummings SR, Stone KL et al.: Risk factors for a first-incident radiographic vertebral fracture in women $\geq 65$ years of age: the study of osteoporotic fractures. J Bone Miner Res 2005; 20:131-140. 10.1359/JBMR.041003

12. Francis RM, Baillie SP, Chuck AJ et al.: Acute and longterm management of patients with vertebral fractures. QJM 2004; 97:63-74.

13. Lyritis GP, Mayasis B, Tsakalakos $\mathrm{N}$ et al.: The natural history of the osteoporotic vertebral fracture. Clin Rheumatol 1989;8:66-69.

14. Francis RM, Aspray TJ, Hide G et al:: Back pain in osteoporotic vertebral fractures. Osteoporos Int 2008; 19:895-903. 10.1007/s00198-007-0530-x

15. Truumees E, Garfin SR. Patient selection in the treatment of pathologic compression fractures. Vertebroplasty and Kyphoplasty. Resnick DK, Garfin SR (ed): Thieme, New York 2005, 48-61.

16. Park YS, Kim HS. Prevention and treatment of multiple osteoporotic compression fractures. Asian Spine J 2014; 8:382-390. 10.4184/asj.2014.8.3.382

17. Old JL, Calvert M. Vertebral compression fractures in the elderly. Am Fam Physician 2004;69:111-116.

18. Lentle BC, Brown JP, Khan A et al. Recognizing and reporting vertebral fractures: reducing the risk of future osteoporotic fractures. Can Assoc Radiol J 2007; 58:2736.

19. Barker KL, Javaid MK, Newman M et al. Physiotherapy rehabilitation for osteoporotic vertebral fracture (PROVE): study protocol for a randomised controlled trial. Trials. 2014, 15:22. Accessed: December 22, 2014: http://www.trialsjournal.com/content/15/1/22

20. Kondo KL. Osteoporotic vertebral compression fractures and vertebral augmentation. Semin Intervent Radiol. 2008; 25:413-424.

21. Marshall D, Johnell O, Wedel H. Meta-analysis of how well measures of bone mineral density predict occurrence of osteoporotic fractures. BMJ 1996; 312:1254-1259. 10.1136/bmj.312.7041.1254

22. Diamond TH, Champion B, Clark WA. Management of acute osteoporotic vertebral fractures: a nonrandomised trial comparing percutaneous vertebroplasty with conservative therapy. Am J Med 2003; 114:257-265. 10.1016/S0002-9343(02)01524-3

23. Tohmeh AG, Mathis JM, Fenton DC, Levine AM, Belkoff SM. Biomechanical efficacy of unipedicular versus bipedicular vertebroplasty for the management of osteoporotic compression fractures. Spine 1999; 24:17721776

24. Marx WF, Schweikert P, Jensen ME, Kallmes DF. Short Term Clinical Complication Rate of Percutaneous Vertebroplasty for Osteoporotic Compression Fractures: Analysis of 462 Treated Levels. Proceedings of the 40th Annual Meeting of the American Society of Neuroradiology, Vancouver, BC, Presentation 2002; 85:76.

25. Hulme PA, Krebs J, Ferguson SJ, Berlemann U. Vertebroplasty and kyphoplasty: a systematic review of 69 clinical studies. Spine 2006; 31:1983-2001.

26. Schnitzler CM. Histomorphology of osteoporosis, in An's Orthopaedics Issues in Osteoporosis, Florida, USA:
CRC press 2003, 19-37.

27. Halvorson TL, Kelley LA, Thomas KA, Whitecloud TS. 3rd, Cook SD. Effects of bone mineral density on pedicle screw fixation. Spine 1994; 19(21):2415-20.

28. Hu S. Internal Fixation in the Osteoporotic Spine. Spine1997; 22(24):43-8

29. Ferara LA, McCormick WE. Biomechanics of Interbody Fusion in Osteoporotic Spine, in An's Orthopaedics Issues in Osteoporosis, Florida,USA: CRC Press 2003, 371-82.

30. Moon MS, Choi WT. Stabilization of Fractured Thoracic and Lumbar Spine with Cotrel-Dubousset instrument.J Orthop Surg 2003; 11(1):59-66

31. Daniaux H. Transpedicular Repositioning and Spongiosaplasty in Fracture of the Vertebral Bodies of the Lower Thoracic and Lumbar spine. Unfallchirurg 1986; 89(5):197-213.

32. Grados F, Depriester C, Cayrolle G, Hardy N, Deramond H, Fardellone P. Long-term observations of osteoporotic fractures treated by percutaneous Vertebroplasty. Rheumatol 2000; 39(12):1410-4. 